\title{
The Motivation of Eighth Grade Students When They Learn the Parallelogram Subject in a Computerized Environment
}

\author{
Nabil Assadi ${ }^{1}, \&$ Sherif Ganem ${ }^{2}$ \\ ${ }^{1}$ Department of Mathematics Education, Sakhnin College for Teachers’ Education, Sakhnin, Israel. \\ ${ }^{2}$ Department of Science Education, Sakhnin College for Teachers' Education, Sakhnin, Israel \\ Correspondence: Nabil Assadi, Department of Mathematics Education, Sakhnin College for Teachers' Education, \\ Sakhnin, 2173, Israel, IL.
}

Received: June 15, 2021

Accepted: July 5, 2021

Available online: August 4, 2021

doi:10.11114/ijsss.v9i5.5263

URL: https://doi.org/10.11114/ijsss.v9i5.5263

\begin{abstract}
The goal of the current study is to examine the impact of the computerized technological environment on the motivation of eighth graders while learning the subject of parallelogram, and whether there are differences in the level of motivation of students who studied parallelogram in a computerized environment and those who studied the same subject in a traditional school environment. The use of the semi-experimental descriptive analytical curriculum, which consisted of a sample of (30) eighth grade students who were selected in a deliberate manner was implemented. The main study tool is a set of pretests and posttests, along with a computerized intervention unit that is meant to enhance students' motivation. The results of the study clearly indicate that the involvement of the computerized environment contributed to raising the students' level of mastery of parallelogram as a subject in eighth graders by raising internal motivation. In light of the findings of the study, the researcher recommends adopting the results of the research, handling the computerized environment as an integral part of the educational system, and qualifying the teacher to be able to actively work within a computerized environment.
\end{abstract}

Keywords: motivation, technology enhanced education, eighth grade, parallelogram

\section{Introduction}

From a very young age, students deal with quadrilateral geometric shapes, such as rectangles, parallelograms, etc., and in this study the focus was on parallelograms in particular, where students, especially those of early age, find it difficult to distinguish it from other quadrilateral geometric shapes, draw it, identify its properties, and solve questions associated with it. The reasons behind learning difficulties in this particular context can be summed up as follows: relying on old-fashioned, traditional teaching techniques, improper use of educational methods that are meant to help students attain a better understanding of mathematics, in addition to the fact that school curricula do not involve adequate suspense and motivation in the educational process at large. As a result of these difficulties, mathematics teaching methods were numerous, and research in this area increased in order to reach to the point where instructors and educators could feel confident that they are in fact teaching mathematics properly. Laws and rules of pure mathematics do not necessarily need to be controlled and memorized; rather students are the party that needs to be motivated.

For the last two decades, literature, constantly pointed to the importance of technology-intensive teaching and technology-enhanced education because of their positive impact on mathematics learning, where the technological environment creates an atmosphere of excitement and motivation among students, and provokes their skills and enthusiasm, leading to increased achievement (Lazarides et al. 2019, 2020). Consequently, students with greater motivation usually exhibit more outstanding educational features than their less motivated peers. The prior emphasizes the importance of promoting student motivation towards math learning, as noted in the (Weidinger et al. 2017) study.

\section{Study Problem}

Problem of the current study is essentially the presence of low levels of motivation of students when dealing with mathematical subjects in general, and parallelograms in particular. When students are exposed to the subject of parallelograms in the traditional way, it has been observed that their levels of motivation and their sense of suspense are 
notably low knowing that mathematical subjects and domains require a deeply-motivated understanding in order for students to employ those notions it in real life.

The objective of the current study is to examine the impact of the computerized environment on the motivation of eighth graders when they learn subjects such as parallelograms, and to point out statistically significant differences in students' motivation when using the computerized environment in the learning process of parallelograms in particular.

\subsection{Study Questions}

The current study attempts to answer the following questions:

1. Is there a statistically significant relationship between the use of the computerized environment and the motivation of eighth-graders when they learn a parallelogram-related subject?

2. Are there statistically significant differences in student motivation when involved in a computerized environment while learning a parallelogram-related subject for eighth-graders attributable to gender?

\subsection{Significance of the Study}

The importance of the current study is firstly highlighted in the fact that the study tackles an educational Aspect deemed vital by many pedagogic experts and educators which is teaching mathematical subjects in technologically rich and/or enhanced environment. Secondly, the study introduces an original content in the field of teaching and learning that aims to enrich providing the previously existing literature with new educational research on such important matters. It also recognizes modern methods that may help boost student motivation and increase their inner desire for math learning, which positively affects their achievement.

\subsection{Study Limits}

\subsubsection{Population}

Eighth grade students at Elementary School (B) in Deir al-Assad village-Northern Israel.

\subsubsection{Time Limits}

Second Semester of the scholastic year 2020.

\subsubsection{Spatial Boundaries}

The application of the study was limited to Arab schools in Northern Israel were all students, administration and staff are Arabic-Speaking citizens.

\subsubsection{Subject Limits}

The current study was limited to identifying the impact of the computerized technological environment on the motivation of eighth graders, while learning about parallelogram-related subjects.

\subsection{Terminology}

- Motivation: Normally defined as the ability to attract learners' attention, and enhance their level of effectiveness in interacting with the activities assigned by the teacher. The priors are performed by the learner himself upon the teachers' request, through active interaction with all available educational components. It is an internal condition of the learners, which directs their thoughts and awareness towards to the educational content by carry out activities related to it, and continuing to perform these activities until the overall goals are fully met (Sabri, 2020).

- Learning difficulties: they are defined as minor and major obstacles to achieving the desired goals of the learning process. There might also be a very specific difficulty or set of difficulties associated with the pupil himself, the learning process in general, teaching methods or the prevailing climate within the school at large.

- Educational achievement: Is the information gained by the student and the skills that he have been developed while learning school subjects. The students' own grades, in this particular respect, could be the teachers' best tool to actually measure their overall achievement.

- Computerized Environment: The researcher defines it as an environment rich in modern educational means that contribute to the lightening of students' horizons and serve as a means of clarification for students and help the teacher explain the subjects of mathematics thoroughly and properly.

- Computerized Learning: It is defined as a process of implementing certain educational content using a computer within a technology-rich or/and technologically enhanced learning environment. 
- Parallelogram: It is a quadrilateral shape in which each side is parallel to the one opposite.

- Deir al-Assad: It is a Palestinian village located on the northern side of Palestine at the foot of Moghor Mount in the Upper Galilee.

\section{Background to Study, Educational Literature and Previous Studies Associated with It}

\subsection{Motivation}

Motivation for learning is an internal, or external, force that provokes the learner's behavior directing it towards achieving the goal of learning. It could also be defined as the desire to gain the highest level of knowledge possible to achieve the educational goal (Al-Jabri, 2012). It can therefore be a feature or a situation; as a feature, it is the activity and energy to achieve a goal, which is to obtain knowledge and maintain participation in the learning process constantly. The prior may not linked to a position as it comes from the learner's inner self to obtain more knowledge and experience, increase his attention to getting the best results in learning, invest in his abilities effectively, and address all the difficulties that hinder the achievement of his goals.

Motives are essentially divided into two categories; unlike external activities and behaviors for reasons of dissatisfaction, these reasons may relate to external rewards, or certain punishment, which means that external motives are based on a form of coercion rather than being self-inflicted (Ryan \& Deci, 2020).

\subsubsection{The Importance of Motivation in Mathematics Education}

Mathematics, which involves highly accurate processes, is often unappealing for many students, affecting their understanding of mathematical concepts and their overall educational achievement (Awofala, 2017). Mathematics is also regarded as an important science in our daily lives, especially in the current era, so students should be aware of this importance because it helps raise their motivation while learning mathematics. As studies have indicated, motivation plays a pivotal role in learning mathematics, improving self-competence and increasing students' interest in participating in math-related events (Rodríguez et al, 2020).

Some studies have confirmed that increased motivation enriches students' mathematical concepts and increases their active participation in the classroom at large,thus enhancing their mathematical performance and raising their educational achievement (Serhan \& Almeqdadi, 2020).

Therefore, we conclude from the information mentioned above, that motivation develops students' ability to understand the concepts of mathematics, improves their school performance, raises the level of their educational achievement, increases their self-confidence, raises their desire to participate in class during math studies, and enhances communication between students and teachers.

\subsection{Computer as a Means of Teaching Mathematics}

Computer-based education is the types of education where computers and their various educational software programs are heavily involved in the educational process. In mathematics, this principle states that "technology should be used to teach and learn mathematics, led by computers and calculators, because they have a great impact on improving student learning, facilitate data organization and analysis, are to perform calculations accurately and quickly, and can effectively assist learners research all mathematics branches" (Abu Thabet, 2013).

The use of computer and technology in teaching and learning has become an important assistance to the education phase for students. Computers are also essential for teachers to provide students with training and exercises to test their skills, store and analyze data on student learning progress, solve the various educational activities carried out by students, solve problems and model educational processes and simulate complex processes that students are otherwise unable to perform in the absence of a technologically enhanced environment (Abu Thabet, 2013).

\subsection{Computer Usage Patterns in Teaching and Learning}

Computer usage patterns in teaching and learning are divided into two main sets:

- Computer-based learning patterns: computer-based learning or computer-assisted learning is an aspect of computer-based learning that focuses on computers use as a means of learning and a source of knowledge. (Omar, 2014).

- $\quad$ Computer-based teaching patterns: they occur when the teacher or the instructor is the key facilitator of the process of teaching. A teacher or an instructor uses a computer to teach a class where students watch and follow the teacher's instructions via scattered screens around the class room, or work in separate groups (Omar, 2014). 


\subsection{Advantages of Computer Use in Education}

computers nowadays play vital roles when it comes the teaching and learning processes; including: the ability to share and retrieve huge sums of date and information, the ability to visually display information, the high speed of conducting processes in mathematics, the presentation of many opportunities and choices in front of the learners, the ability to control and manage many accessories, as well as the ability to interact with the user (Mansour, 2006).

\subsection{Barriers to Computer Use in Education}

Despite the fact that there are many advantages to computer implementation in education and the educational process in general, there must be some obstacles and difficulties facing process of actively and effectively using computers in education. The most important of the priors is a shortage of human resources specialized in computer science and education, lack of sufficient awareness of its introduction in education and learning, lack of computer-friendly educational programs and software (particularly Arabic language-speaking programmers), as well as the unaffordability of hardware by some students or educational facilities. Provision and maintenance, the preparation of teachers qualified for computer education, and poor computer capacity are other notable obstacles (Jaber, 2007).

\subsection{Reasons for Computer Use in Teaching and Learning}

One of the justifications for using computers in learning and teaching is the fact that the computer is a means of preserving, checking and retrieving information when necessary, the speed of obtaining data, the efficiency in solving problems related to learning difficulties, computer's reliability and accuracy in solving complex mathematical equations and processes, and its ability to helps solve problems in learning difficulties for those with certain disabilities. Computers also help greatly in collecting and analyzing data, presentation of the educational materials in a way that suits the abilities of students and their specific educational needs (Omar, 2014).

\section{The Impact of the Technologically-Rich Environment on Mathematics Education}

The technology-rich environment plays an important role in teaching and learning mathematics. With studies emphasizing that technology raises the cognitive achievement of the students, their ability to retain information, and understanding and application of complex mathematical problems and equasions. Computers have therefore become an integral part of the educational process at large (Western, 2009). Computers can facilitate the process of communication between teachers and students, they can also increase their overall achievement. Generally speaking, a technology-rich environment is in fact an interactive environment that attracts students' attention and interests, and enhances their attitudes toward mathematics as subject (Saidi et al., 2017).

Several related studies have also confirmed that the technology-rich environment increases students' achievement levels, self-esteem, positive attitudes towards mathematics and desire to learn the subject. Students, on the other hand, may have lower interest in the subject if notebooks and textbooks where the sole educational media available for them (Sahin \& Yilmaz, 2020). The technology-rich environment transforms the traditional classroom educational environment into an interactive environment that enhances students' ability to tackle mathematical problems and equations, increases their cognitive skills and mental and motor activity, it is also said to raise their motivation towards learning and their efficiency in the classroom in general (Wallace \&Wilson, 2020). In addition to the prior, the technologically-rich environment can improve students' attitudes towards math learning, help them solve complex problems and equations, support the exploration of mathematical concepts, provide dynamically-linked representations of ideas, and encourage students' potential (Artigue, 2009).

With regard to the performance of academic students in mathematics and its relationship to the use of technology, it has been shown that students' performance is positively influenced by the use of technology, as experimental research has shown that the results of students taught using technology were much higher than those taught in the traditional ways. In addition, this technological environment has increased students' approval and attitudes towards mathematics, which has also contributed to creating a positive interactive atmosphere, and consequently led to improved overall performance (Eyyam \& Yaratan, 2014). Therefore, technology plays an active role in provoking students' abilities and skills, improving their performance and changing their attitudes towards mathematics learning.

\section{The Impact of the Technological Environment on Promoting Students' Motivation}

The processes of language and teaching, when actively and effectively carried out in a computerized technological environment are flexible, efficient, and ultimately beneficial., Technological environment stimulates students' motivation and desire to achieve goals by creating interaction and taking into account individual variations between students, making them willing to accept learning, and stimulates them to excel in the various school subjects (Baetty \&Thomas, 2020). Studies have shown that the computerized and technological environment is a significant part of raising students' motivation and awareness for learning, regardless of whether they are males or females, it has also shown great success in attracting their attention and focus in the various mathematical subjects that were deemed boring 
or/and desirable by the students before (Logani and Al-Radan, 2017).

The previous studies confirm that the technological environment creates a level of interaction and participation among students, which promotes and motivates them to do better in the various school materials, which in one way or another leads to higher educational achievement. The presence of a technological environment has become a necessity of the educational process. Having proven its competence in promoting motivation and raising the awareness and self-reliance of the students, technology-rich teaching and learning environments have become a necessity for the modern-day student and educator, because they takes into account the individual differences between the students and enable the educator to go above and beyond what the conventional conditions of a classroom can actually offer. A technologically-enhanced environment can really promote a higher level of communication between teachers and students, which is an absolute necessity for an efficient educational process (Urbancova \& Fajcikova, 2020).

\section{Method and Procedures}

The current study examines the approach, community and sample of the study, the way the study tool is constructed, its sincerity and stability, and the statistical methods used to analyze the data.

\subsection{Methodology}

To achieve the objectives of this study, the researcher followed the semi-experimental descriptive analytical approach that in fact suits the nature of this study.

\subsection{Community and Sample Study}

The sample consists of all the eighth grade students of an Arab school in Israel that was selected in a deliberate manner, with a sample size of 30 students, a total of 13 male students and 17 female students.

\subsection{Study Tool}

In this study, the researcher used the test as a starting point for a study. A pretest and a posttest were conducted separately. The tests include a set of questions related to a parallelogram study scheduled for eighth grade mathematics, each of which includes (5) comprehensive questions for the subject of parallelogram and the student must answer four questions of them. Both groups will be subjects to both tests prepared and conducted by the researcher. The control group of the study consists of those who learned mathematics in the traditional way. The experimental group consists of those who received education in a computerized, technologically-rich environment. A grade out of (20) was calculated for both tests separately, knowing that the test was developed in a way that suits the levels of students and takes into account the individual variations between them (see annex 1).

Table 1. Analysis of pretest paragraphs (a)

\begin{tabular}{|c|c|}
\hline $\begin{array}{l}\text { Question } \\
\text { Number }\end{array}$ & Goal \\
\hline S.1 & $\begin{array}{l}\text { - The student should learn about the concept of parallelograms and their characteristics. } \\
\text { - The student should recognize the midpoint property and its equivalent in any aspect of the geometric shapes. } \\
\text { - } \quad \text { Retermine the relationship between the opposite sides in the parallelogram. } \\
\text { - } \quad \text { The student distinguishes the shape of a parallelogram from other geometric shapes. }\end{array}$ \\
\hline S. 2 & $\begin{array}{l}\text { - The student recognizes the relationship between parallel sides in parallelogram. } \\
\text { - } \quad \text { Finding a measurement of parallel angles the student knows the measurement of its one angle. } \\
\text { - The student should recognize the property that each two correspondent sides in a parallelogram are equal in } \\
\text { length. } \\
\text { The student should recognize the property that each two correspondent angles in a parallelogram are equal in } \\
\text { value. }\end{array}$ \\
\hline S. 3 & $\begin{array}{l}\text { - Review of diameters (perpendicular, equal, and in a middle position to each other) and angles and their types. } \\
\text { - } \quad \text { Recognizing the midpoint property of parallel diagonal diameters. } \\
\text { - The student must be able to prove that parallel sides on one of the diagonals result in two identical triangles. } \\
\text { - The student should conclude that each diameter in a parallelogram is in a middle position to the other. }\end{array}$ \\
\hline S.4 & $\begin{array}{l}\text { - The student should retrieve the proof of the theory of parallel diagonals. Each diameter divides the parallels into } \\
\text { two identical triangles. } \\
\text { - The student must prove the theory of the parallelogram by matching triangles. } \\
\text { - The student should be able to recognize the equal opposite angles in the parallellogram. } \\
\text { - The student should be able to recall the characteristics of the parallelogram. } \\
\text { The student should know that each two opposite sides of the parallelogram are equal in length. }\end{array}$ \\
\hline S.5 & $\begin{array}{l}\text { - Recognizing the containment relationship between geometric shapes and quadrants. } \\
\text { - } \quad \text { Reviewing the quadrants, their qualities, their characteristics, their diameters, and their angles. } \\
\text { The student should distinguish between the parallelogram shape and other geometric shapes. }\end{array}$ \\
\hline
\end{tabular}


Table 2. Analysis of posttest paragraphs (b)

\begin{tabular}{|c|c|}
\hline $\begin{array}{l}\text { Question } \\
\text { Number }\end{array}$ & Goal \\
\hline S.1 & $\begin{array}{l}\text { - The student should know that the total value of angles of the quadrant shape combined is } 360 \text { degrees. } \\
\text { - The student should restore the characteristics of the parallelogram. } \\
\text { - The student should find parallel angles if he is told the value of just one angle. } \\
\text { - The student should mention the angle type if he or she knows its value. } \\
\text { - The student should recognize the law of parallel circumference. } \\
\text { - Check the proof of opposite and even angles in the parallelogram. } \\
\text { - Check the proof of the opposite sides in the parallelogram. }\end{array}$ \\
\hline S.2 & $\begin{array}{l}\text { - The student should know the concept of the parallelogram. } \\
\text { - } \quad \text { Development of student and logical mathematical capabilities (conclusion, analysis, implementation). } \\
\text { - The student should know how to find parallel angles. } \\
\text { - } \quad \text { Recognize the opposite angles. } \\
\text { - The student must find the midpoint between two opposite sides. } \\
\text { To recognize the characteristic of cross-side diameters at a midpoint. }\end{array}$ \\
\hline S.3 & $\begin{array}{l}\text { - Identify special cases of parallelogram. } \\
\text { - } \quad \text { Identify the intersection of parallel diagonal diameters. } \\
\text { - } \quad \text { Leview the properties of parallelogram and diameters. } \\
\text { - The student must prove that each diameter is equal to the other in a parallelogram. }\end{array}$ \\
\hline S.4 & $\begin{array}{l}\text { - The student must be able to prove a characteristic that each two opposite angles are equal. } \\
\text { - The student should know that each two opposite angles complete each other, i.e. a total of } 180 \text { degrees. } \\
\text { - The student retrieves and measures the types of angles (straight, obtuse, acute, and right). } \\
\text { - The student should learn about what constitutes a quadrant. } \\
\text { - To recognize a property that parallel sides in a parallelogram are equal in length }\end{array}$ \\
\hline S.5 & $\begin{array}{l}\text { - The student should know special cases of a parallelogram. } \\
\text { - To restore the characteristics, properties and distinctive features of quadrants. } \\
\text { - To recognize a common side in a parallelogram. } \\
\text { - To identify the characteristics of parallelograma, opposite and even sides in a parallelogram. }\end{array}$ \\
\hline
\end{tabular}

The referees' honesty method was used to determine the sincerity of the test after the they agreed to the validity of the test to be applied to two research groups after the required modifications were carried out.

- $\quad$ Test stability

The pretest and posttest stability factor was approximately $(0.83)$, a high stability factor that confirms the validity of the tests used in the research.

\section{- $\quad$ Statistical treatment}

The researcher relied on the use of the statistical analysis program (SPSS) to analyze the results by figuring out mathematical averages and standard deviations to determine the level of motivation for students when learning in a computerized environment. T-test for pairs and t-test for independent samples to obtain parity between the experimental and control groups were carried out. Another t-test was also carried out to see if there are any statistically significant differences depending on the gender variable.

\section{Results}

To answer the study's questions, the researcher formulated the following hypotheses:

\subsection{Theorem I}

There are statistically significant differences in the "motivation of eighth graders when they learn the subject of parallelogram within a computerized environment" between the pretest and posttest where t-testing was conducted and the standard rates and deviations of research variables were calculated as shown in Table 1.

Table 3. Averages and standard deviation, $\mathrm{t}$-value, and statistical indication of the pre and posttests marks where $\mathrm{n}=30$

\begin{tabular}{|c|c|c|c|c|c|c|}
\hline & \multicolumn{2}{|l|}{ Pretest } & \multicolumn{2}{|l|}{ Posttest } & \multirow[b]{2}{*}{ t-value } & \multirow{2}{*}{$\begin{array}{l}\text { Statistical } \\
\text { significance }\end{array}$} \\
\hline & Average & $\begin{array}{l}\text { Deviation } \\
\text { Normative }\end{array}$ & Average & $\begin{array}{l}\text { Standard } \\
\text { deviation }\end{array}$ & & \\
\hline Total mark & 63.12 & 8.73 & 87.70 & 8.75 & 84.91 & 0.00 \\
\hline
\end{tabular}


The results of the table above show that the average of posttests (rate 87.70) and standard deviation (8.75) is higher than the pretest which was at (average 63.12). These differences between the two tests are statistically significant at $\left(\mathrm{t}_{(29)}=\right.$ 84.91, $\mathrm{p}<0.01)$.

To examine the second research hypothesis, "There are no statistically significant differences in the motivation of eighth graders when they learn the subject of parallelogram between the control group and the experimentation in the posttest", the t-test was conducted and the standard rates and deviations of the research variables were calculated as shown in Table 3.

Table 4, Averages and standard deviations, $t$-value and statistical indication of the marker of the control and experimental groups in the pretest

\begin{tabular}{lllllll}
\hline & \multicolumn{2}{l}{$\begin{array}{l}\text { Control Group } \\
\text { No.30 }\end{array}$} & \multicolumn{3}{l}{ Experimental Group } \\
& Average & $\begin{array}{l}\text { Deviation } \\
\text { Normative }\end{array}$ & Average & $\begin{array}{l}\text { Standard } \\
\text { deviation }\end{array}$ & t-value & Statistical significance \\
\cline { 2 - 7 } Total mark & 60.41 & 10.42 & 63.12 & 8.73 & 1.09 & 0.28 \\
\hline
\end{tabular}

The results of the table above show that the average of the pretest among the students of the controlling group in a subject of parallelogram is low (average 60.4, standard deviation 10.42). The posttest average among the students of the experimental group in the subject of parallelogram is also low at (average 63.12). These differences between rates are not statistically significant at $\left(\mathrm{t}_{(29)}=1.09, \mathrm{p}>0.05\right)$.

To examine the third research hypothesis, "There are statistically significant differences in the motivation of eighth graders when they learn the subject of parallelogram between males and females" the t-test was conducted and the average and standard deviations of the research variables were calculated as shown in Table 3.

Table 5, Averages and standard deviations, t-value and statistical indication of male and female markers

\begin{tabular}{|c|c|c|c|c|c|c|}
\hline & \multirow{2}{*}{\multicolumn{2}{|c|}{$\begin{array}{l}\text { Males } \\
\text { No.13 }\end{array}$}} & \multirow{2}{*}{\multicolumn{2}{|c|}{$\begin{array}{l}\text { Females } \\
\text { No. } 17\end{array}$}} & \multirow{3}{*}{ t-value } & \multirow{3}{*}{ Statistical significance } \\
\hline & & & & & & \\
\hline & Average & $\begin{array}{l}\text { Deviation } \\
\text { Normative }\end{array}$ & Average & $\begin{array}{l}\text { Standard } \\
\text { deviation }\end{array}$ & & \\
\hline Total mark & 91.34 & 8.28 & 84.92 & 8.28 & 2.10 & 0.04 \\
\hline
\end{tabular}

The results of the table above show that the test rate in the subject of parallelogram in male students (average 91.34, standard deviation 8.28) is higher than the test rate in female students (average 84.92, standard deviation 8.28). These differences between rates are statistically significant at $\left(\mathrm{t}_{(28)}=2.10, \mathrm{p}<0.05\right)$.

We will present in the following examples that have been selected to show the level of students, their interaction and motivation in the answers of the pretest and similarly, in the posttest based on the intervention program presented.

\subsubsection{Models of Pretesting}

Figure 1 shows that the solution of the second question carried out by a student, the student achieves the specific objectives of the question, namely, finding a measurement of parallel angles if one angle is known, and that the sum of each two adjacent angles is equal to 180 . Besides, the student was able to determine the characteristic that each side is equal to its opposite counterpart. 


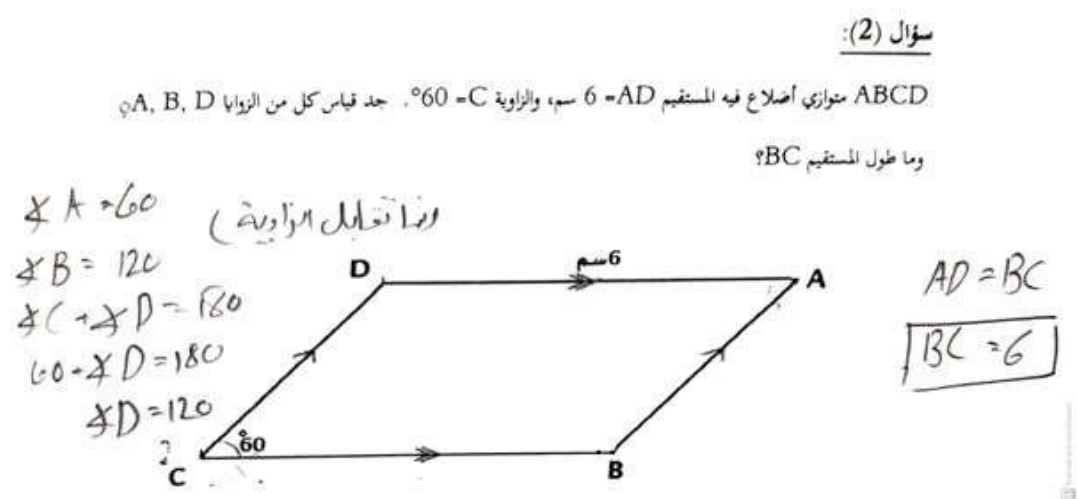

Figure 1. A student's answer to the second question of the pretest through which the objective of the question is achieved.

(Finding the required lengths of the sides and the measurement of the angle)

As Figure 2 shows, the solution of the first question of a student does not confirm the extent to which he understands the relationship between the opposite sides in the parallelogram and the characteristic of the midpoint in these shapes. The student should have mentioned that the opposite sides are equal and therefore, dividing them in halves would yield equal halves, so the quadrant shape in which there are two parallel and equal opposite sides is in fact a parallelogram.

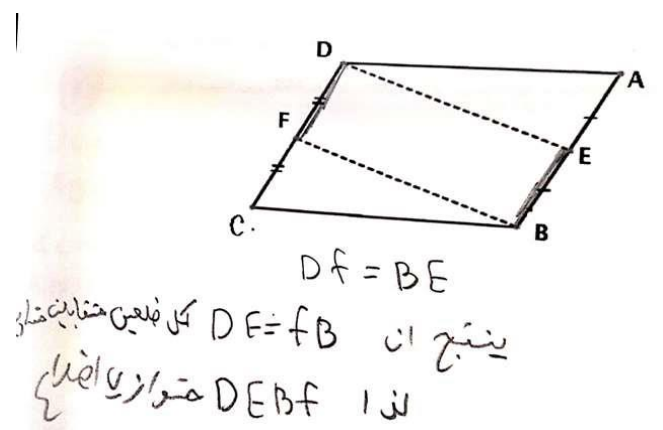

Figure 2. A student's answer to the first question of the pretest without understanding the relationship between the corresponding sides in a parallelogram

While figure 3 shows the solution of the first question of a different student, I found that he was able to understand the characteristics of parallelogram, where by matching the triangles, he was able to prove that the shape is in fact a parallelogram. Depending on the theory that in quadrant shapes if it is achieved that each two opposite sides are equal then it is indeed a parallelogram. 


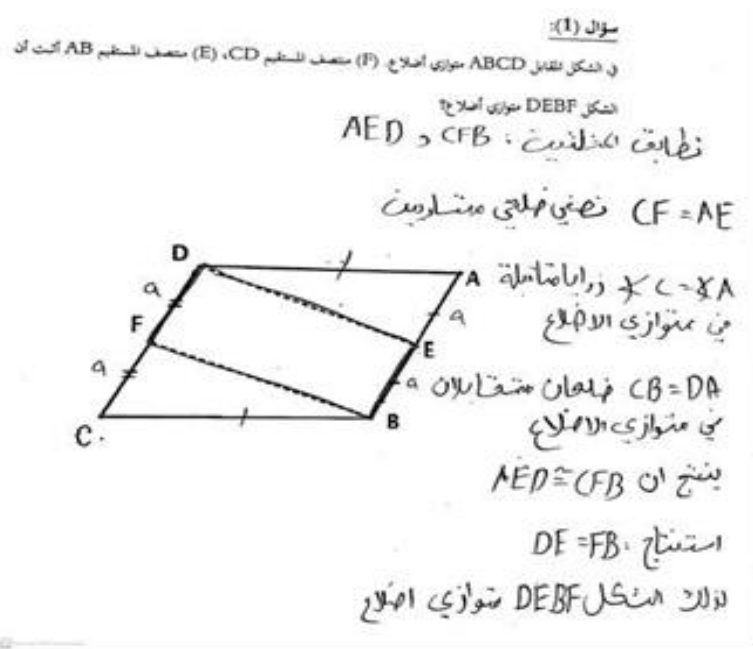

Figure 3. An answer provided by another student to the first question of the pretest

Figure 4 shows the student's answer to the attached question is in fact short and undetailed. However, it is a correct answer. The answer demonstrates that the student understand the characteristics related to the parallel diagonal as each diameter exactly halves the other. The characteristic of the meeting point of two sides and the relationship between the opposite and adjacent angles in the parallelogram are obviously comprehended by the student.

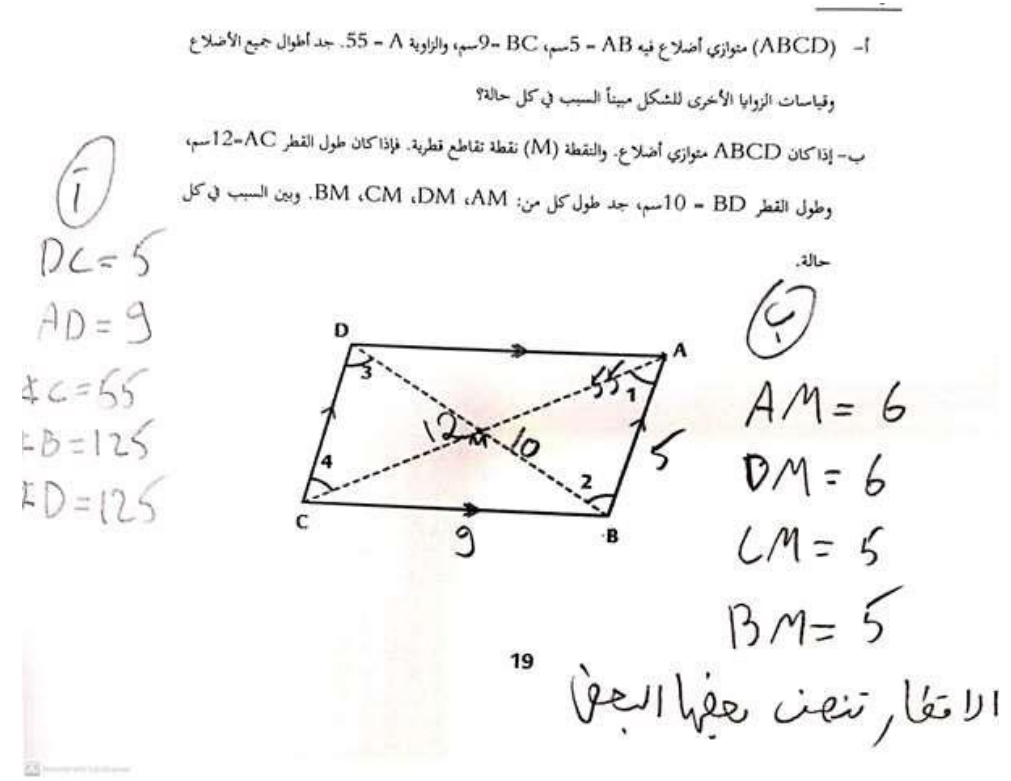

Figure 4. A short, but sufficient and correct answer provided by one of the students in the pretest

In figure5, a gap appears in a student's solution to the fifth question due to his lack of full discrimination of the shape of a parallelogram. He was able to identify only two out of three shapes, knowing that by solving it, he seems to be able to recognize the containment relationship between the geometric and quadrant forms, as well as the characteristics of parallelogram that are related to its sides, so the solution was not a complete one. 


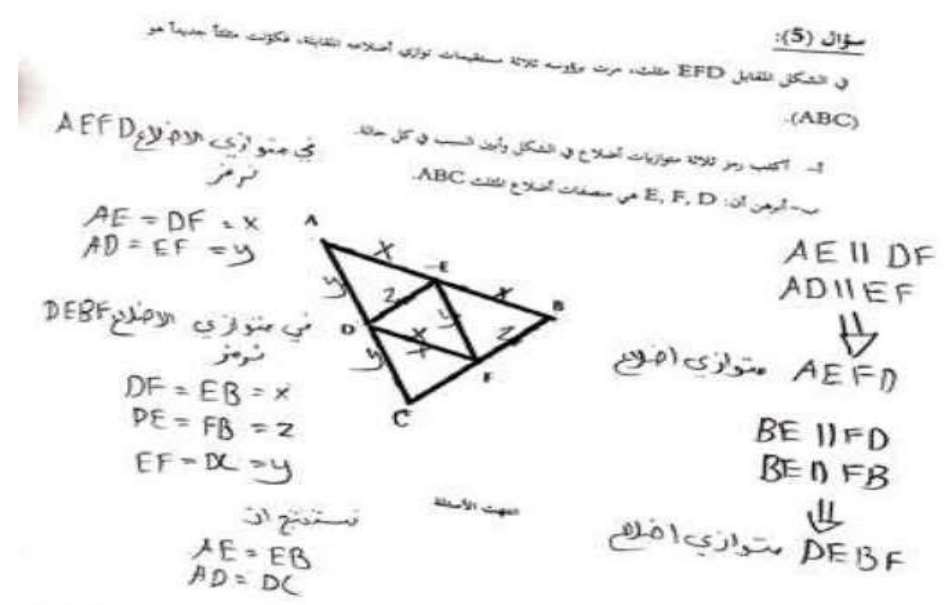

Figure 5. A student's answer to the fifth question of the pretest. The answer shows that the student is not in fact able to differentiate between the parallelogram and other geometric shapes

figure (6) represents another student's solution of the same How Effective is Mathematical Modeling in a technological environment and its impact on developing Motivation Toward Learning Mathematics Among Students in Middle Schools in Rahat-Negev region. The student was found unable to recognize the parallelogram as a shape, where he could only identify one parallelogram of the three given in the question and referred to the trapezoid as being a parallelogram. The origin of the error lays is in the lack of understanding of the distinctive features of the geometric shape, which was a major reason for not reaching the correct result.

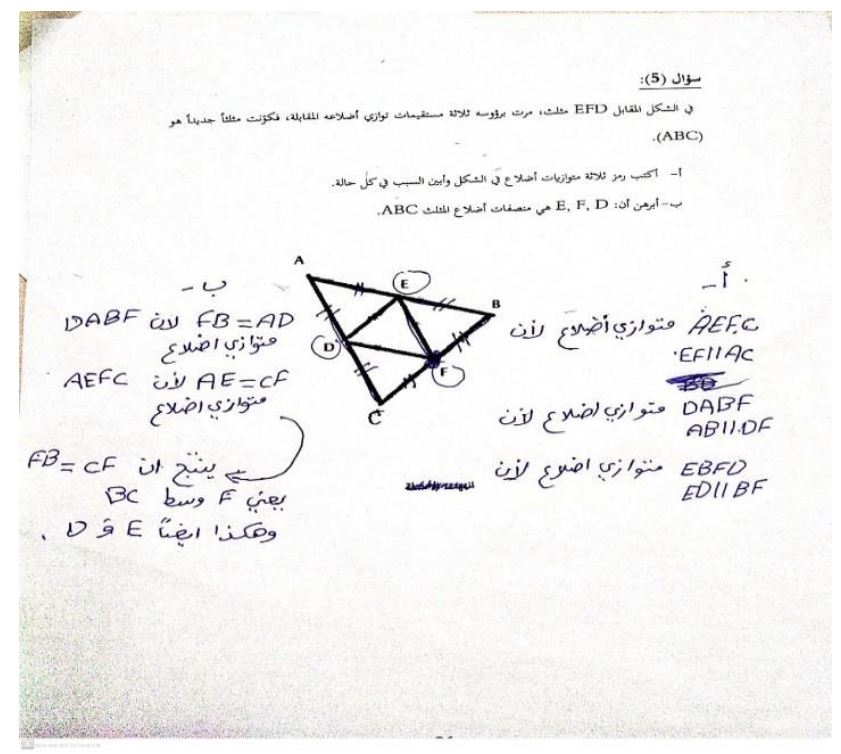

Figure 6. Another student's answer to the fifth question which shows that the student is unable to define the concept of the parallelogram

By solving the fourth question in figure 7, the student exhibited that he was able to understand the matching of triangles depending on the characteristics of parallelograms and its angles to prove of what was required. 


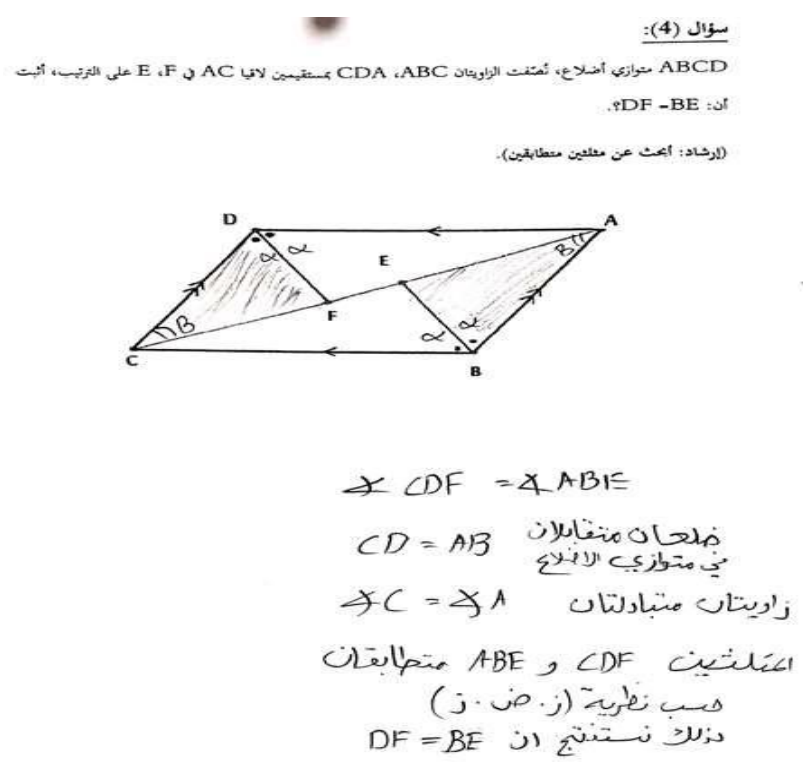

Figure 7. A student's answer to the fourth question of the pretest which shows the student's ability to understand the characteristics of the parallelogram

\subsubsection{Models Post Testing}

The figures $(8,9,10,11$, and 12) show the students' motivation and a significant improvement in the level of apparent solutions.

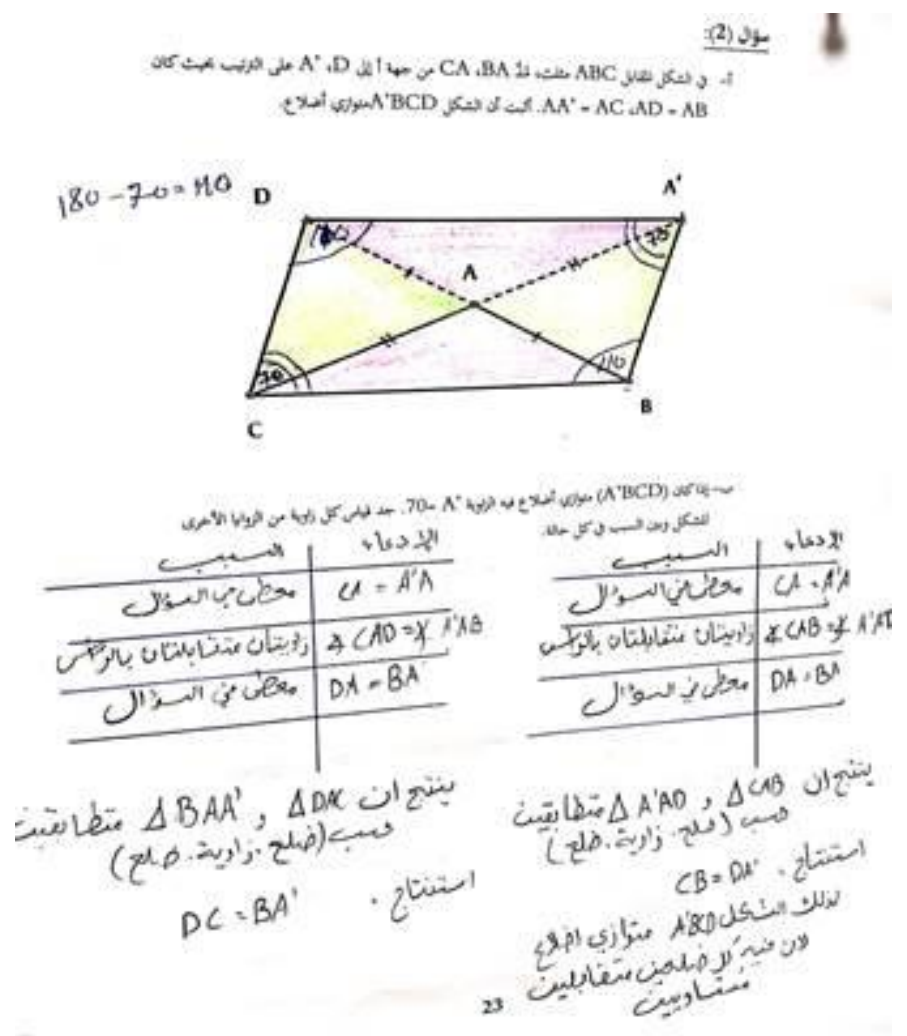

Figure 8. A student's answer to the second question of the posttest which shows the student's ability to understand the characteristics of the parallelogram 


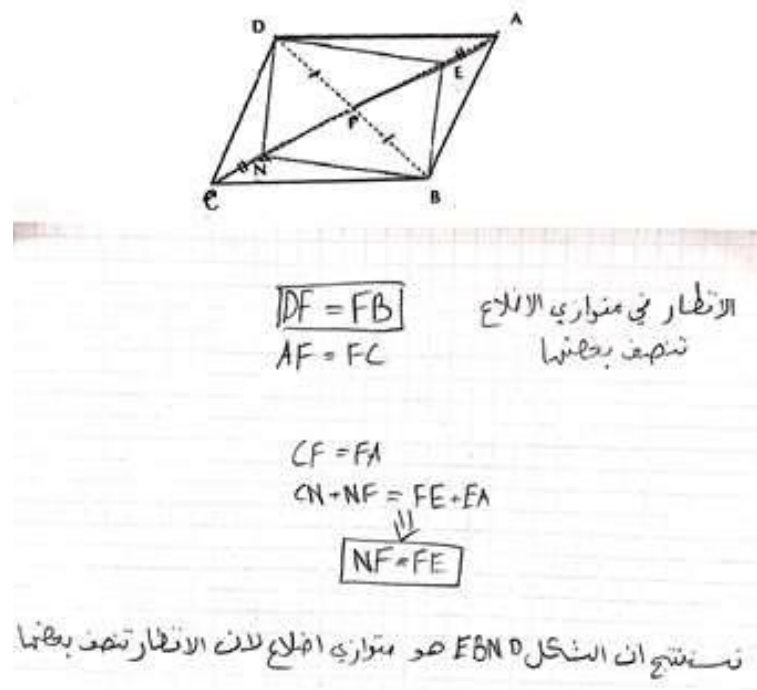

Figure 9. A student's answer to the third question of the posttest which shows the student's ability to understand the characteristics of the parallelogram

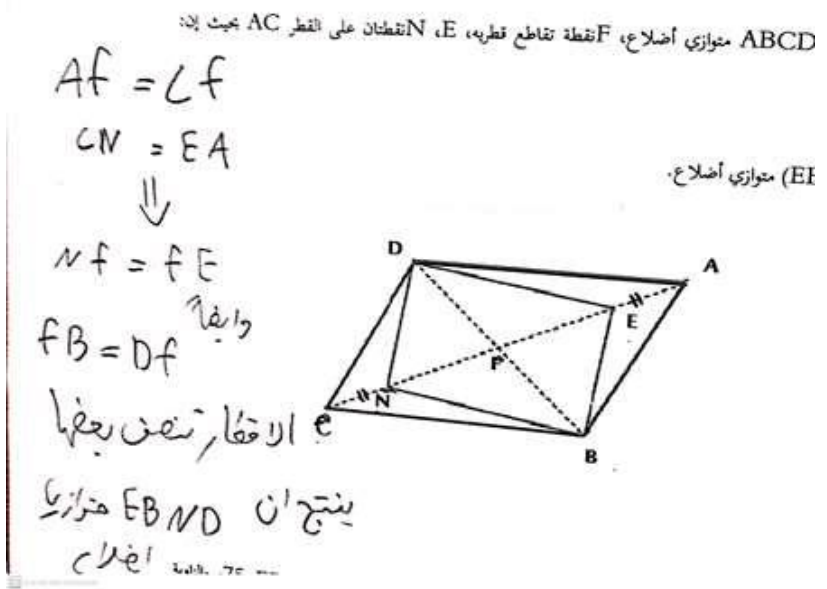

Figure 10. A student's answer to the third question of the posttest which shows the student's ability to understand the characteristics of the parallelogram 


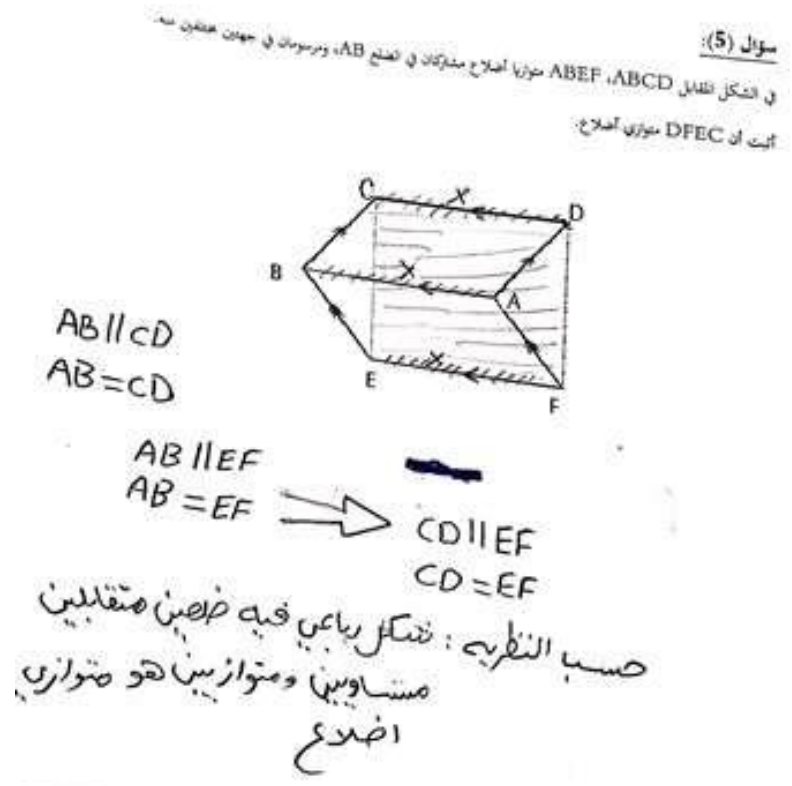

Figure 11. A student's answer to the fourth question of the posttest which shows the student's ability to understand the characteristics of the parallelogram

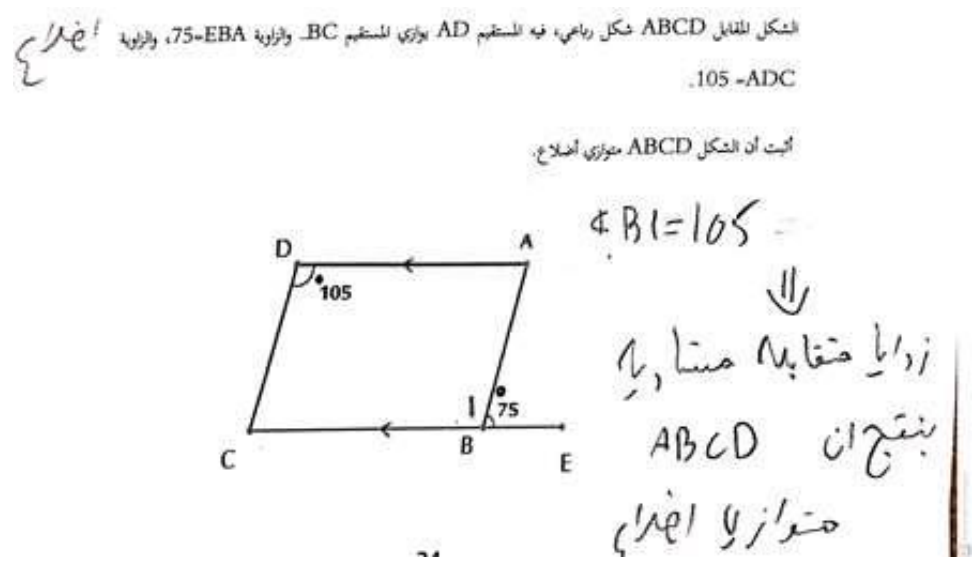

Figure 12. A student's answer to the fifth question of the posttest which shows the student's ability to understand the characteristics of the parallelogram

\section{Discussion}

The results of the study can be explained according to previously-conducted research papers that were presented in the literature review. They almost all agree on the positive effect of technology-rich computerized environment on the students' achievements, educational attainment, motivation and desire to learn. Engaging technology might break the ice and gradually extinguish the fear that many students hold of mathematics.

Motivation plays an important role in the teaching and learning of mathematics. Based on the change and improvement in the computerized educational environment, it has increased the motivation of students, thus increased their ability to interact with the teacher, their ideas, awareness and attention at large are also positively stimulated. The computerized environment contains different motivations that raise students' motivation, especially internal self-motivation (Ryan\& Deci, 2017). Since mathematics involves very precise processes that might be frightening to tackle to students, this affects their understanding of mathematical concepts and their scientific achievement in this subject (Awofala, 2017). The computerized environment is an environment that helps facilitate these processes and convey a more accurate and simultaneously interactive understanding of mathematical processes. Computer education and technology are important assistance to students' educational achievement in general; they are used to solve problems, model educational processes and simulate complex processes as well (Abu Thabet, 2013).

The contribution of the computerized environment in helping to develop students' performance and achievement can be explained through the use of technology within the educational process itself. Students exhibit a better understanding of 
the subject, they find it easier to deal with, and the overall sense of difficulty diminishes within a computerized environment. It is worth mentioning that the technology-rich environment plays an important role in teaching mathematics, raising the cognitive achievement, enhances information retaining properties, and improves understanding and application (Western, 2009). The prior also facilitates the process of communication between teachers and students because it is an interactive environment that attracts students' attention and interest, and enhances their attitudes towards mathematics in general. (Saidi, 2017) Studies have also confirmed that the technology-rich and interactive environment increases students' achievement levels notably, helps them achieve self-satisfaction, and positively-influences their attitudes towards mathematics. Students learning in the traditional textbook-only way have exhibited lower achievements and less interest and motivation towards the subject (Sahin \& Yilmaz). On the other hand, this environment (computerized, technology-rich environment) improves student attitudes and might even help explore their potential (Artigue, 2009).

\subsection{Recommendations}

In light of these findings of the study, the researcher recommends adopting the method of education in the computerized environment on a large scale. It has been shown that this kind of settings helps the student to improve their overall educational achievement because it raises their motivation and arouses their interest in the subject. Within this environment, teachers can find numerous resources to diversify their teaching methods, break the monotony of the class, and make complex mathematical questions easier to handle. The study also recommends that teachers should be entitled to advanced and specialized training in software programs that help manage a technology-rich, computerized environment.

\section{References}

Abu Thabet, E (2013). The effectiveness of the use of the Geogebra program and educational means in direct and deferred achievement among students in the ninth grade of mathematics in public schools in Nablus governorate. a published master's thesis, Graduate School, Al-Rajah University, Nablus-Palestine.

Al-Jabri, N. (2012). The level of use of applications, software and computers among university students, and its association with motivation towards e-learning. The Journal of Farahidi Literature. Tikrit University, 12, 459-492.

Artigue, M. (2009). The future of teaching and learning mathematics with digital technologies. In Mathematics Education and Technology-Rethinking the Terrain, 463-475. https://doi.org/10.1007/978-1-4419-0146-0_23

Awofala, A. at al. (2020) Motivation to Learning Mathematics and Gender as Correlates of Senior Secondary School Students' Performance in Mathematics. Journal of Educational Sciences, 4(2), 318-333. https://doi.org/10.31258/jes.4.2.p.318-333

Awofala, A., \& Lawani, A. (2020). Increasing Mathematics Achievement of Senior Secondary School Students through Differentiated Instruction. Journal of Educational Sciences, 4(1), 1-19. https://doi.org/10.31258/jes.4.1.p.1-19

Beatty, B., \& Thomas, M. (2020). English Language Learner Motivation in the Digital Technology Classroom: A Case Study of a Vocational University in Indonesia. In Recent Developments in Technology-Enhanced and Computer-Assisted Language Learning ,pp. 184-207. IGI Global. https://doi.org/10.4018/978-1-7998-1282-1.ch009

Eyyam, R., \& Yaratan, S. (2014) Impact of use of technology in mathematics lessons on student achievement and attitudes. Social Behavior and Personality, 42(1), 32-42. https://doi.org/10.2224/sbp.2014.42.0.S31

Ibanez, M. at al. (2020) Impact of augmented reality technology on academic achievement and motivation of students from public and private Mexican schools. A case study in a middle-school geometry course. Computers \& Education, 145, 103734. https://doi.org/10.1016/j.compedu.2019.103734

Jaber, W. (2007). The impact of computer use on the achievement of seventh-grade students in mathematics and the trends of their teachers towards its use as an educational tool. a published master's letter, National University of Success, Nablus- Palestine.

Lazarides, R. et al., (2019) Stability and change in students' motivational profiles in mathematics classrooms: The role of perceived teaching. Teaching and Teacher Education, 79(13). https://doi.org/10.1016/j.tate.2018.12.016

Logani, A., \& Al-Radan, D. (2017). The impact of the interaction between the use of smart classrooms and the specialization in the development of learning motivation for students of the Faculty of Education for Basic In Kuwait. International Specialized Educational Journal, 6(6).

Mansour, M. (2006). The impact of a computerized programs on the development of engineering conversion skills among 10th graders in Gaza. a published master's thesis, department of curriculum and teaching methods, Islamic University, Gaza-Palestine.

Montero, C., Barbado, D., \& Cervello, E. (2020). Predicting bullying through motivation and teaching styles in physical 
education. International journal of environmental research and public health, 17(1), 87. https://doi.org/10.3390/ijerph17010087

National Mathematics Advisory Panel (NMAP). (2008) Foundations for success: The final report of the national Mathematics advisory panelWashington, DC: U.S. Department of Education. Retrieved from https://www2.ed.gov/about/bdscomm/list/mathpanel/ report/final-report.pdf

Omar, E. (2014). The impact of the use of "D Cabri 3" on the achievement of eighth-grade students in the engineering unit, and their motivation for learning them in schools south of Nablus. a published master's thesis, Al-Najah National University, Nablus-Palestine.

Rodríguez, S., Regueiro, B., Piñeiro, I., Estévez, I., \& Valle, A. (2020) Gender Differences in Mathematics Motivation: Differential Effects on Performance in Primary Education. Frontiers in Psychology, 10, 3050. https://doi.org/10.3389/fpsyg.2019.03050

Ryan, R. M., \& Deci, E. L. (2017). Self-determination theory: Basic psychological needs in motivation, development, and wellness. New York, NY: Guilford Publishing.

Ryan, R. M., \& Deci, E. L. (2020). Intrinsic and extrinsic motivation from a self-determination theory perspective: Definitions, theory, practices, and future directions. Contemporary Educational Psychology, 101860. https://doi.org/10.1521/978.14625/28806

Sabri, M. (2020). The phenomenon of losing student motivation in Teaching Arabic at The Charity High School, Mowar Jambi. Arabic Language magazine and Islamic Culture Education, 1(1), 1-11.

Sahin, D., \& Yilmaz, R. M. (2020). The effect of Augmented Reality Technology on middle school students' achievements and attitudes towards science education. Computers \& Education, 144, 103710. https://doi.org/10.1016/j.compedu.2019.103710

Saidi, M. Al-Balushi, M. et al. (2017). The impact of e-education in mathematics teaching on educational attainment and the trend towards the subject among fifth graders of basic education in Oman. International Specialized Educational Journal, 6(4).

Serhan, D., \& Almeqdadi, F. (2020). Students' Perceptions of Using MyMathLab and WebAssign in Mathematics Classroom. International Journal of Technology in Education and Science, 4(1), 12-17. https://doi.org/10.46328/ijtes.v4i1.23

Urbancova, H., \& Fajcikova, A. (2020). Factors influencing students' motivation to study at a university. International Journal of Education Economics and Development, 11(1), 27-36. https://doi.org/10.1504/IJEED.2020.104286

Wallace, A. H., \& Wilson, D. R. (2020). Mathematical Literacy and Young Children: Incorporating Technology in the Early Childhood Classroom. In Handbook of Research on Integrating Digital Technology With Literacy Pedagogies (pp. 313-344). IGI Global. https://doi.org/10.4018/978-1-7998-0246-4.ch014

Weidinger, A., Steinmayr, R., \& Spinath, B. (2017). Math grades and intrinsic motivation in elementary school: A longitudinal investigation of their association. British Journal of Educational Psychology, 87, 187-204. https://doi.org/10.1111/bjep.12143

Western, J. (2009). The impact of teaching using electronic classes in the three manifestations on the achievement of fifth grade students in mathematics. master's thesis, Um al-Qura University, Mecca.

\section{Copyrights}

Copyright for this article is retained by the author(s), with first publication rights granted to the journal.

This is an open-access article distributed under the terms and conditions of the Creative Commons Attribution license which permits unrestricted use, distribution, and reproduction in any medium, provided the original work is properly cited. 